\title{
Importance and Satisfaction of Destination Attraction for Water-Based Tourism in Jeju Island
}

\author{
Jaeyoon Kwon ${ }^{1}$, Taerin Chung ${ }^{2}$, Sang Hwa Yoon ${ }^{3} \&$ Kwan Bae Kwon ${ }^{3}$ \\ ${ }^{1}$ Global Center for Arts \& Culture Education, Sangmyung University, Seoul, Republic of Korea \\ ${ }^{2}$ Department of Sports Industry Studies, Yonsei University, Seoul, Republic of Korea \\ ${ }^{3}$ Department of Taekwondo, Yongin University, Yongin, Republic of Korea \\ Correspondence: Kwan Bae Kwon, Yongin University. E-mail: kwon-gun@hotmail.com
}

Received: August 10, 2017

Accepted: August 18, $2017 \quad$ Online Published: September 28, 2017

doi:10.5539/ass.v13n10p1

URL: https://doi.org/10.5539/ass.v13n10p1

\begin{abstract}
The purpose of this study was to verify importance and satisfaction of destination attraction for water-based tourism in Jeju Island using Importance-Performance Analysis (IPA). The participants of this study consisted of 429 water-based tourism participants who visited Jeju Island in Korea. The collected data were analyzed and interpreted using SPSS program, frequency analysis, exploratory factor analysis, reliability analysis, and Importance-Performance Analysis. The results of this study were as follows. First, quadrant 1 included in season and climate comfort, local souvenirs, and hospitality of tourism program guide. Second, quadrant 2 included six items with sports activities rental facilities, scenic viewing activity, hospitality of local residents, accessibility of the island, convenience of local island transportation, and tourism safety. Third, quadrant 3 included four items with congestion of sightseeing spot, the reputation of a tourist destination, amusement facilities, affordable price, and traditional foods Fourth, quadrant 4 included eight items with marine related experience training activity, coastal landscape and terrain, marine sports activity, accommodation and shopping facilities, marine festivals and events activity, rest and recreational activity, history and cultural heritage, and service facilities.
\end{abstract}

Keywords: importance, performance, destination attraction, water-based tourism, Jeju Island

\section{Introduction}

The tourism industry is globally recognized as the single largest business (Haber \& Reichel, 2005). Among various types, water-based tourism is attracting attention as the fastest growing industry. Recently, as marine leisure and marine sports have become popular and demand for them has increased, tourism centered on marinas and coasts has emerged (Collinces, 2008; Hall, 2001), as a highly interesting common phenomenon in Europe, North America, and many island nations. For this purpose, development of a tourism business model related to oceans is under way (Dawson, Maher \& Slocombe, 2007). Water-based tourism is also recognized as a highly addictive tourism sector (Orams, 2002), which has been spotlighted for ocean-based leisure activities including, motor boating, scuba diving, fishing, windsurfing, yachting, and other marine sports.

Certain regions, for instance, Australia, Europe, Japan, and the United States, have very high water-based tourism participation rates (Smith \& Stewart, 2007). Until a few years ago, however, on the Korean peninsula the development rate was very low, and participation rates were low compared with the global trend Nevertheless, the Korean government is now at the planning stage for appreciating and utilizing marine resources' growth potential. In particular, it plans to nurture water-based tourism and cruise and marina industries into tourism service industries (Chang, Park, Liu, \& Roh, 2016). As such, water-based tourism resources reflect Korea's spatial and socio-cultural characteristics. Therefore, the Korean government should actively develop water-based tourism to improve local residents' quality of life promote local economic development, and the tourism industry in general (Kim \& Ryu, 2009).

Indeed, Korea's natural environment shows that the tourism industry is highly likely to grow. Korea has 3,170 islands, $11,542 \mathrm{~km}$ of coastline, $2.39 \mathrm{~km}^{2}$ of mud flats, 2,240 fish ports and catchments, and 306 beaches. In addition, about 70 large and small marine festivals and sporting events are held at scenic maritime locations around the country (Lee \& Yeo, 2007). Additionally, in coastal areas, water-based tourism is actively sought as an alternative to urban and regional economic development. As an example, Jeju, is Korea's largest island, and 
Jeju's most famous sightseeing locations attract not only Korean but also Japanese and Chinese tourists. The number of visitors to Jeju Island is expected to reach 10 million in 2013 and exceed 15 million in 2016. This number is also expected to increase as the number of tourists to Southeast Asia and neighboring countries increases. Furthermore, factors that attract increasing numbers of tourists to Jeju Island are as follows. First, tourists from neighboring countries, Japan and China, for instance, can easily visit the island because of low-cost, direct flights. Second, the social network service (SNS) for residents and tourists on Jeju has become an active means of publicity. Third, the number of marine and cruise tourists have increased. Finally, the number of tourists has surpassed 1.2 million and is expected to increase with various events and programs this year (Jeju Tourism Organization, 2016).

To compete as a tourist destination, Korea needs a broad approach to tourism planning (Hunter, 1997). Grasping what tourists value and how they form experiences and evaluate expectations is necessary (Litvin\& Ling, 2001). Generally, since tourism experience begins with strong impressions of tourist destinations and places visited, innovative creation and proactive management of attractions are necessary to maintain the resources' positive attraction and experiences, which are the key elements of tourist sites (Oh \&Ko, 2006).Until now, however, previous studies have focused on increasing the number of external visitors, but have not been able to improve the satisfaction of tourist sites by evaluating those visited internally. Therefore, continuous and efficient assessment of attractiveness can improve the tourists' level of satisfaction. In particular, Jeju's high likelihood of offering water-based tourism can actively establish a direction for efficient tourism development and management, as well as help create policy alternatives for attracting tourists. Importance-Performance Analysis (IPA) IPA understands the satisfaction of tourists with a simple statistical method and can prioritize the improvement of service quality. Particularly, by presenting strengths and weaknesses, efficient distribution of goods, services, resources, and competitiveness of tourism destinations can be clearly diagnosed. Thus, it was judged to be suitable for this study.

Therefore, this study evaluates water-based tourism's attractiveness on Jeju Island, using Importance-Performance Analysis (IPA) a relatively useful technique for evaluating tourist attractions and searches for improved directions based on analysis results suggesting alternatives to the island's current tourism policy.

\section{Literature Review}

\subsection{Island Tourism}

In the mid- $20^{\text {th }}$ century, island tourism began with the technological revolution and air transportation, which made far-flung islands reasonable destinations for tourism and its development (Bell \& Bramwell, 2005). In particular, geographical isolation, a unique culture, and an attractive climate and environment are an island's main attractions. The distinctive natural ecosystem and unique lifestyle, differentiation, small scale, unique culture, wild ecosystem, marginal life, and primitive environment are characteristic of island tourism (Baum, 1999; Buhalis \& Costa, 2006). However, island mysteries are disappearing due to the construction of commercial resorts and accommodations, artificial beaches, and irreverent golf courses. According to Twining-Ward and Butler (2002), expansion of tourism through development directly impacts the size of an island's economy, but for sustainability of island tourism, local residents and tourists should highly appreciate its attractiveness.

\subsection{Destination Attraction}

Tourists generally consider all of their destinations before traveling (Kozak \& Rimmington, 1998). Thus, destination attraction is significantly influenced by others' recommendations and motivation to revisit a location (Enright \& Newton, 2004). To attract tourists, the destination must appeal to the tourists more than other destinations. Leisen (2001) reported that destination attraction has more scope than enjoy for beautiful scenery and fails as a tourist destination without the attraction factor. In addition, Richards (2003) indicated that tourism attraction is necessary because most tourists classify destination attraction as a cross-cultural and intercultural experience as they attempt to experience something different and more colorful than there, perhaps, routine and repetitive lives.

\subsection{Water-Based Tourism}

Water-based tourism specifically relates to any touristic activity undertaken in relation to water resources: lakes, dams, canals, creeks, streams, rivers, waterways, marine coastal zones, seas, oceans, and ice-associated areas (Jennings, 2007). Although not clearly defined at present, many researchers have defined water-based tourism as a very comprehensive, diverse concept. However, definitions commonly used in previous studies involve activities to pursue changes in marine and coastal areas, the main motive of tourism activities, and activities that 
take place in marine spaces and places (Hall, 2001; Orams, 1988). In terms of the global marine industry's growth, its size is expected to increase by $55.2 \%$ from US $\$ 232.2$ billion in 2010, to US $\$ 360.3$ billion in 2020 (Dowling, 2006). Accordingly, regions that can expect coastal development Australia, China, Europe, and Japan - are paying attention to water-based tourism combined with marine leisure, sports, and infrastructure, for instance cruises, marinas, yachts, and so on, as new tourism resources (Leiper, 2004).

\subsection{Importance-Performance Analysis}

Since its introduction by Martilla and James (1977), marketing research analysts have widely used IPA to measure satisfaction through customer-satisfaction surveys (Matzler, Bailom, Hinterhuber, Renzl, \& Pichler, 2004; Martilla \& James, 1977). In particular, it has been applied to tourism resource development policy evaluation and planning (Evans \& Chon, 1989), followed by image and package travel evaluation, park facilities' evaluation, and outdoor-recreation ski-resort research (Hudson \& Shephard, 1998; Pike, 2002). Previous studies' characteristics are that the research subject evaluates tourism objects and analyzes tourism sites with complex characteristics. IPA measures the significance and performance of evaluation elements (Figure 1), displays them on two-dimensional drawings, and assigns meaning according to the position. In quadrants divided by a center point, IPA can be expressed as "concentrate here," "keep up the good work," "low priority," and "possible overkill” (Hosseini \&Bideh, 2014; Rial, Rial, Varela, \& Real, 2008).

Quadrant 1: Contains the attributes that are perceived to be very important to customers, and the organization seems to provide high levels of performance. Thus attributes in this quadrant are referred to as the major strengths and opportunities for achieving or maintaining competitive advantage.

Quadrant 2: Contains the attributes that are perceived as low importance to customers, but the organization seems to provide high levels of performance. In this case, the organization should reallocate resources committed to attributes in this quadrant to other quadrants in need of improved performance.

Quadrant 3: Contains the attributes with low importance and low performance which are referred to as the minor weak-nesses. Thus attributes in this quadrant do not require a great deal of priority for improvement.

Quadrant 4: Contains attributes that are perceived to be very important to customers but performance levels are fairly low. These attributes are referred to as the major weaknesses that require immediate attention for improvement.

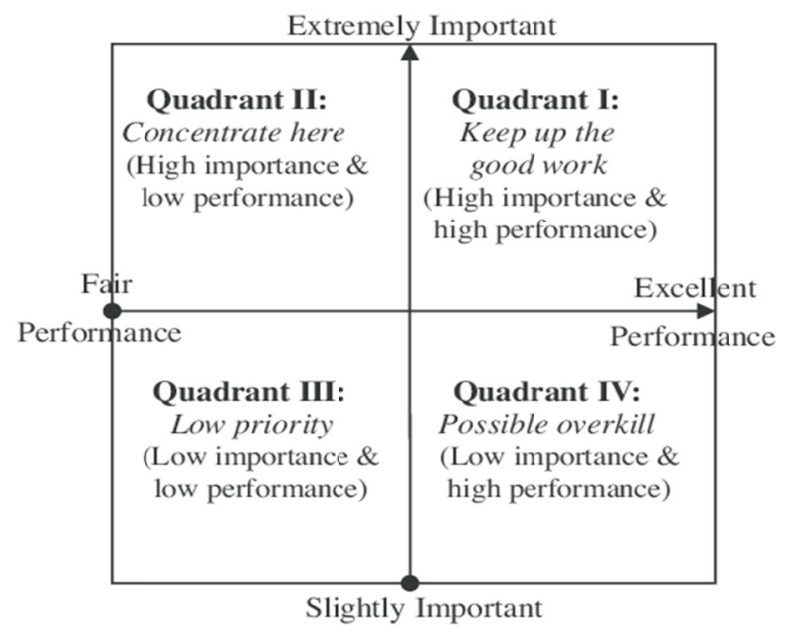

Figure 1. The Importance-Performance Analysis (IPA) matrix (Hosseini \& Bideh, 2014).

\section{Materials and Method}

\subsection{Subject of the Study}

To examine importance and performance analysis of destination attraction for water-based tourism in Jeju Island, from May to August 2016, adult tourists who participated in water-based tourism in Jeju Island were selected as subjects. A convenience, non-random sampling method was used to select participants. In total, 435 questionnaires were distributed, and of these, 11 were eliminated based on a lack of information and low validity. Thus, data in 429 questionnaires were analyzed. A summary of the general characteristics of the study is shown in Table 1. 
Table 1. General characteristics of the subjects of the study

\begin{tabular}{|c|c|c|c|}
\hline Characteristics & Classification & $\mathrm{N}$ & $\%$ \\
\hline \multirow{4}{*}{ Age } & 20 's & 108 & 25.2 \\
\hline & 30 's & 214 & 49.8 \\
\hline & 40 's & 73 & 17.1 \\
\hline & Over 50 & 34 & 7.9 \\
\hline \multirow{3}{*}{ Stay duration (days) } & $1-2$ & 118 & 27.5 \\
\hline & $2-3$ & 235 & 54.7 \\
\hline & $3-4$ and more & 76 & 17.8 \\
\hline \multirow{3}{*}{ Transportation } & Rental car & 381 & 88.9 \\
\hline & Tour bus & 34 & 7.9 \\
\hline & Tour taxi & 14 & 3.2 \\
\hline \multirow{3}{*}{ Information } & Advertising & 58 & 13.5 \\
\hline & SNS & 233 & 54.3 \\
\hline & Acquaintance & 138 & 32.2 \\
\hline \multirow{3}{*}{ Experience } & $1^{\text {st }}$ time & 214 & 49.9 \\
\hline & 1-3 times & 109 & 25.4 \\
\hline & Over 4 times & 106 & 24.7 \\
\hline
\end{tabular}

\subsection{Research Procedure}

The primary research method adopted in this study was the questionnaire method (survey). Table 2 outlines characteristics of the questionnaire. Questionnaire items included 5 questions pertaining to demographic characteristics, 22 focusing on importance of destination attraction, and 22 on satisfaction of destination attraction. Importance and satisfaction of destination attraction variables are composed with activity, convenience, facility, local and historical, natural environment, and hospitality. 22 items assessed destination attraction based on study by Ab Karim \& Chi (2010) and Enright \& Newton (2004) was translated and modified for this study. Questionnaires were measured on a five-point Likert scale ranging from 'Strongly disagree' (1) to 'Strongly agree' (5).

Table 2. Questionnaire characteristics

\begin{tabular}{|c|c|c|c|}
\hline Configuration Index & Content & Number of Questions & Total \\
\hline \multirow{5}{*}{$\begin{array}{l}\text { Demographic } \\
\text { Characteristics }\end{array}$} & Age & \multirow{5}{*}{5} & \multirow{5}{*}{5} \\
\hline & Stay duration & & \\
\hline & Transportation & & \\
\hline & Information & & \\
\hline & Experience & & \\
\hline \multirow{6}{*}{$\begin{array}{c}\text { Satisfaction of Destination } \\
\text { Attraction }\end{array}$} & Activity & 5 & \multirow{6}{*}{22} \\
\hline & Convenience & 5 & \\
\hline & Facility & 4 & \\
\hline & Local and historical & 4 & \\
\hline & Natural environment & 2 & \\
\hline & Hospitality & 2 & \\
\hline \multirow{6}{*}{$\begin{array}{c}\text { Satisfaction of Destination } \\
\text { Attraction }\end{array}$} & Activity & 5 & \multirow{6}{*}{22} \\
\hline & Convenience & 5 & \\
\hline & Facility & 4 & \\
\hline & Local and historical & 4 & \\
\hline & Natural environment & 2 & \\
\hline & Hospitality & 2 & \\
\hline & Total & & 49 \\
\hline
\end{tabular}




\subsection{Validity and Reliability Tests}

The validity and reliability of the study were verified through an expert discussion on the questionnaire items. To access the questionnaire's content validity, 80 questionnaires were distributed. Of these, 7 were eliminated because of a lack of information. Therefore, 73 were used in the preliminary research. Despite that the test value in this study was verified in earlier work, it was re-verified to ensure a better result.

Regarding construct validity and to verify questionnaire reliability, and exploratory factor analysis and reliability analysis were conducted. With principal factor analysis for factor extraction, the varimax rotation method was based on an eigenvalue of 1.0 or more, while selected items had factor values of .6 and more. To verify the reliability of the study, Cronbach's $\alpha$ coefficient was used, and to determine if internal consistency was acceptable. Table 3 provides the results of the exploratory factor analysis.

Table 3. Results of the validity test: importance and satisfaction of destination attraction

\begin{tabular}{|c|c|c|c|c|}
\hline Factor & Variable & Factor loading & Eigen-value ( $\%$ of Variance) & $\alpha$ \\
\hline \multirow{5}{*}{ Activity } & Marine related experience training activity & .894 & \multirow{5}{*}{$\begin{array}{c}3.542 \\
(14.763)\end{array}$} & \multirow{5}{*}{.868} \\
\hline & Marine festivals and events activity & .879 & & \\
\hline & Rest and recreational activity & .863 & & \\
\hline & Marine sports activity & .841 & & \\
\hline & Scenic viewing activity & .820 & & \\
\hline \multirow{5}{*}{ Convenience } & Convenience of local island transportation & .845 & \multirow{5}{*}{$\begin{array}{c}3.304 \\
(13.764)\end{array}$} & \multirow{5}{*}{.811} \\
\hline & Accessibility of the island & .821 & & \\
\hline & Tourism safety & .792 & & \\
\hline & Affordable price & .777 & & \\
\hline & Congestion of sightseeing spot & .718 & & \\
\hline \multirow{4}{*}{ Facility } & Service facilities & .816 & \multirow{4}{*}{$\begin{array}{c}3.108 \\
(12.950)\end{array}$} & \multirow{4}{*}{.807} \\
\hline & Sports activities rental facilities & .815 & & \\
\hline & Amusement facilities & .813 & & \\
\hline & Accommodation and shopping facilities & .792 & & \\
\hline \multirow{4}{*}{ Local and historical } & Local souvenirs & .801 & \multirow{4}{*}{$\begin{array}{c}2.731 \\
(11.392)\end{array}$} & \multirow{4}{*}{.783} \\
\hline & The reputation of a tourist destination & .797 & & \\
\hline & History and cultural heritage & .765 & & \\
\hline & Traditional foods & .735 & & \\
\hline \multirow{2}{*}{ Natural environment } & Coastal landscape and terrain & .773 & 2.684 & \multirow{2}{*}{.761} \\
\hline & Season and climate comfort & .758 & $(11.175)$ & \\
\hline \multirow{2}{*}{ Hospitality } & Hospitality of local residents & .731 & 2.316 & \multirow{2}{*}{.720} \\
\hline & Hospitality of tourism program guide & .719 & $(9.714)$ & \\
\hline
\end{tabular}

\subsection{Data Process}

The remaining 429 questionnaires were used in the statistical analysis, which was conducted using SPSS version 22.0. The analysis method was as follows. First, for the general features of the study, a frequency analysis was carried out. Second, to assess the validity of the study, an exploratory factor analysis was conducted. Third, to verify the importance and satisfaction degree difference of water-based tourism of destination attraction, and analyzed the importance and satisfaction of destination attraction through IPA matrix.

\section{Results}

\subsection{Importance-Satisfaction and Priority Analysis of Water-Based Tourism Destination Attraction.}

The water-based destination attractions of importance-satisfaction and priority results were shown in Table 4 . The average importance of hospitality was 3.62, which was the most importance, followed by convenience (3.38), environment (3.29), local and historical (3.17), activity (3.11), and facility (3.03). Specifically, 'hospitality of tourism program guide' was the highest in hospitality, followed by 'convenience of local island transportation' in convenience, 'season and climate comfort' in natural environment, 'local souvenirs' in local and historical, marine related experience training activity' in activity, and 'sports activities rental facilities' in facility. Satisfaction of natural environment was the highest in the average 3.32, followed by natural environment 
(3.27), facility (3.06), hospitality (3.00), activity (2.98), local and historical (2.92), and convenience (2.75). Specifically, 'coastal landscape and terrain' was the highest in natural environment, followed by 'marine related experience training activity' in activity, 'accommodation and shopping facilities' in facility, 'hospitality of tourism program guide' in hospitality, 'history and cultural heritage' in local and cultural, and congestion of sightseeing spot' in convenience.

Table 4. Importance-satisfaction and priority analysis of water-based tourism destination attraction

\begin{tabular}{|c|c|c|c|c|c|c|c|}
\hline \multirow{2}{*}{ Factor } & \multirow{2}{*}{ Questionnaires } & \multicolumn{3}{|c|}{ Importance } & \multicolumn{3}{|c|}{ Satisfaction } \\
\hline & & Rank & $M$ & $S D$ & Rank & $M$ & $S D$ \\
\hline \multirow{5}{*}{ Activity } & 1. Marine related experience training activity & 13 & 3.10 & 1.213 & 1 & 3.66 & 1.271 \\
\hline & 2. Marine festivals and events activity & 16 & 3.06 & 1.321 & 6 & 3.24 & 1.281 \\
\hline & 3. Rest and recreational activity & 11 & 3.21 & .931 & 7 & 3.18 & 1.423 \\
\hline & 4. Marine sports activity & 20 & 2.67 & 1.004 & 4 & 3.28 & 1.429 \\
\hline & 5. Scenic viewing activity & 7 & 3.51 & .915 & 13 & 3.00 & .976 \\
\hline \multirow{5}{*}{ Convenience } & 6. Convenience of local island transportation & 2 & 3.71 & .861 & 20 & 2.58 & 1.234 \\
\hline & 7. Accessibility of the island & 4 & 3.68 & .792 & 18 & 2.88 & 1.131 \\
\hline & 8. Tourism safety & 8 & 3.43 & .854 & 22 & 2.51 & 1.071 \\
\hline & 9. Affordable price & 18 & 3.03 & 1.083 & 19 & 2.85 & 1.073 \\
\hline & 10. Congestion of sightseeing spot & 14 & 3.09 & 1.012 & 15 & 2.93 & 1.213 \\
\hline \multirow{4}{*}{ Facility } & 11. Service facilities & 12 & 3.11 & .961 & 10 & 3.08 & 1.489 \\
\hline & 12. Sports activities rental facilities & 1 & 3.83 & .887 & 12 & 3.01 & .938 \\
\hline & 13. Amusement facilities & 22 & 2.56 & .977 & 17 & 2.90 & .955 \\
\hline & 14. Accommodation and shopping facilities & 21 & 2.65 & 1.017 & 5 & 3.25 & 1.598 \\
\hline \multirow{4}{*}{$\begin{array}{l}\text { Local and } \\
\text { historical }\end{array}$} & 15. Local souvenirs & 9 & 3.36 & .938 & 9 & 3.12 & 1.302 \\
\hline & 16. The reputation of a tourist destination & 15 & 3.07 & 1.101 & 16 & 2.91 & 1.214 \\
\hline & 17. History and cultural heritage & 10 & 3.22 & .930 & 8 & 3.15 & 1.610 \\
\hline & 18. Traditional foods & 17 & 3.05 & 1.027 & 21 & 2.53 & 1.075 \\
\hline \multirow{2}{*}{$\begin{array}{c}\text { Natural } \\
\text { environment }\end{array}$} & 19. Coastal landscape and terrain & 19 & 2.92 & 1.235 & 2 & 3.36 & 1.241 \\
\hline & 20. Season and climate comfort & 5 & 3.67 & .792 & 3 & 3.29 & 1.123 \\
\hline \multirow{2}{*}{ Hospitality } & 21. Hospitality of local residents & 6 & 3.55 & .877 & 14 & 2.95 & 1.132 \\
\hline & 22. Hospitality of tourism program guide & 3 & 3.69 & .860 & 11 & 3.06 & 1.236 \\
\hline Total & & \multicolumn{3}{|c|}{3.24} & & \multicolumn{2}{|c|}{3.03} \\
\hline
\end{tabular}

\subsection{IPA Matrix Analysis of Water-Based Tourism Destination Attraction}

IPA was used to compare and analyze the relative importance and satisfaction of each characteristic through the importance and satisfaction of water-based tourism destination attraction. In this study, the method of setting the center point of the axes is based on the median of the maximum and minimum values of the whole averages, and the IPA intersection points are set. The horizontal axis is the satisfaction level and the vertical axis is the importance level (Duke \& Persia, 1996; Martilla \& James, 1997). The results of the analysis were shown in Figure 2 and Table 5.

Table 5. IPA matrix results of water-based tourism destination attraction

\begin{tabular}{ll}
\hline IPA Quadrant & Items \\
\hline Quadrant 1 & Season and climate comfort, local souvenirs, hospitality of tourism program guide \\
\hline Quadrant 2 & $\begin{array}{l}\text { Sports activities rental facilities, scenic viewing activity, hospitality of local residents, accessibility of } \\
\text { the island, convenience of local island transportation, tourism safety }\end{array}$ \\
\hline Quadrant 3 & $\begin{array}{l}\text { Congestion of sightseeing spot, the reputation of a tourist destination, amusement facilities, affordable } \\
\text { price, traditional foods }\end{array}$ \\
\hline Quadrant 4 & $\begin{array}{l}\text { Marine related experience training activity, coastal landscape and terrain, marine sports activity, } \\
\text { accommodation and shopping facilities, marine festivals and events activity, rest and recreational } \\
\text { activity, history and cultural heritage, service facilities }\end{array}$ \\
\hline
\end{tabular}




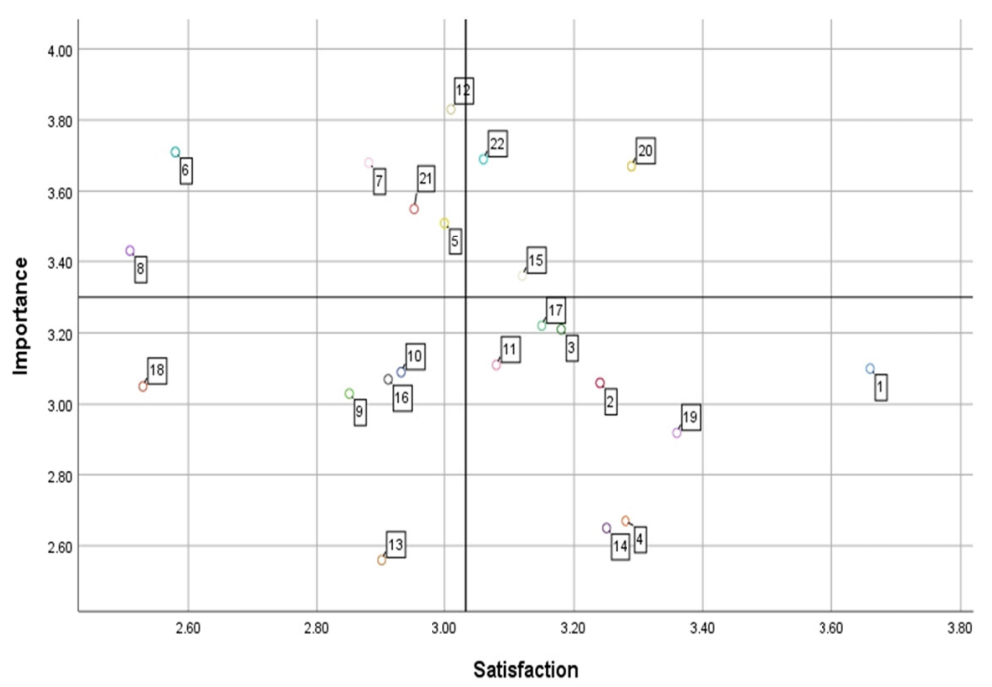

Figure 2. IPA matrix of water-based tourism destination attraction

\section{Discussion and Conclusion}

This study's purpose was to define the destination attraction, using IPA, of water-based tourism in Jeju. The discussion based on the purpose and results follows. First, through IPA analysis, four quadrants were identified based on the average value of destination attraction of water-based tourism importance and satisfaction. Quadrant 1 included three items: season and climate comfort, local souvenirs, and hospitality of tourism program guides. These three items showed both high importance and satisfaction, indicating that management and operation are adequate at present for appropriate climate, local souvenirs, and service-oriented hospitality. Because Jeju is an island, it has a good climate for enjoying wind sports (JeJu Tourism Organization, 2016). Therefore, tourism products such as surfing, windsurfing, and yachting should be developed further. In addition, tour guides' hospitality satisfies tourists' expectations for service quality. The staff and guides' kindness gives satisfaction to tourists (Kwon, 2016), and intangible goods, such as human services, are important in tourists' decision-making (Thornton, Shaw, \& Williams, 1997). Water-based tourism, which has a short period of participation, offers beneficial roles for guides because most of the time is spent with the guide. Therefore, continuous guidance education should lead to participation satisfaction.

Second, Quadrant 2 included six items: sports activities' rental facilities, scenic viewing activity, local residents 'hospitality, island accessibility, convenience of local island transportation, and tourism safety. These six items showed high importance and low satisfaction, indicating that intense efforts are required at present. Water-based tourism should provide rental facilities and programs for various sports because tourists want a variety of experiences. In addition, water-based tourists are inevitably exposed to accidents. Therefore, comfortable safety considerations are crucial (Jennings, 2007).In addition, accessibility and transportation are issues that Jeju Island should resolve. The number of passengers at Jeju Island airport is expected to reach 15.8 million in 2015, 18.7 million in 2020, and become saturated in 2025.In response to surging aviation demand, disadvantages in transportation infrastructure are expected to be resolved through construction of a new international airport (Jeju Tourism Organization, 2016).In transportation, providing convenience through tour or shuttle buses, in addition to rental cars, is necessary.

Third, Quadrant 3 included four items: congestion at sightseeing locations, the reputation of a tourist destination, amusement facilities, affordable prices, and traditional foods. The four items showed low importance and high satisfaction, indicating that these are not priority considerations. In other words, for Quadrant 3, Jeju Island is equipped with all the tourist destination's necessary conditions. Currently, Jeju Island is developing diverse local foods such as horsemeat, pork, and mandarin. However, Jeju Island's products that can attract potential tourists should be continuously developed (Seo, Park, \& Yu, 2009).

Fourth, Quadrant 4 included eight items: marine-related experience training activities, coastal landscapes and terrain, marine sports activity, accommodation and shopping facilities, marine festivals and events, rest and recreational activities, history and cultural heritage, and service facilities. At present, these items should be reconsidered. Environmental factors and various facilities' expansions are well implemented and give tourists great satisfaction. The 2007 UNESCO World Heritage Designation and the 2011 World Seven Natural Landscapes selection indicate that Jeju Island's tourism brand image has risen (Belle \& Bramwell, 2005). Thus, 
the number of domestic and foreign tourists will likely increase. In the long run, continuously developing tourism products that reflect the natural ecosystem and unique living culture are crucial to the island's sustainability as an attractive tourist destination. Previous studies showed the difficulty of defining tourist satisfaction in outdoor leisure services, because tourists may be satisfied with the service in tourism programs but not with their participation. Therefore, a deeper exploration of tourist satisfaction in the water-based tourism context is needed in future research.

\section{References}

Ab Karim, S., \& Chi, C. G. Q. (2010). Culinary tourism as a destination attraction: An empirical examination of destinations' food image. Journal of Hospitality Marketing \& Management, 19(6), 531-555. https://doi.org/10.1080/19368623.2010.493064

Baum, T. (1999). Themes and issues in comparative destination research: The use of lesson-drawing in comparative tourism research in the North Atlantic. Tourism Management, 20(5), 627-633. https://doi.org/10.1016/s0261-5177(99)00037-0

Belle, N., \& Bramwell, B. (2005). Climate change and small island tourism: Policy maker and industry perspectives in Barbados. J. of Travel Research, 44(1), 32-41. https://doi.org/10.1177/0047287505276589

Buhalis, D., \& Costa, C. (Eds.). (2006). Tourism management dynamics: Trends, management and tools. London: Routledge. https://doi.org/10.1057/palgrave.thr.6040057

Chang, Y. T., Park, H., Liu, S. M., \& Roh, Y. (2016). Economic impact of cruise industry using regional input-output analysis: A case study of Incheon. Maritime Policy \& Management, 43(1), 1-18. https://doi.org/10.1080/03088839.2015.1086837

Dawson, J., Maher, P. T., \& Slocombe, S. D. (2007). Climate change, marine tourism, and sustainability in the Canadian Arctic: Contributions from systems and complexity approaches. Tourism in Marine Environments, 4(1), 69-83. https://doi.org/10.3727/154427307784772057

Dowling, R. K. (2006). Cruise tourism: Issues, impacts, and cases. Wallingford, UK: CABI Publishing. https://doi.org/10.1079/9781845930486.0000

Duke, C. R., \& Persia, M. A. (1996). Performance-importance analysis of escorted tour evaluations. Journal of Travel \& Tourism Marketing, 5(3), 207-223. ttps://doi.org/10.1300/j073v05n03_03

Enright, M. J., \& Newton, J. (2004). Tourism destination competitiveness: A quantitative approach. Tourism Management, 25(6), 777-788. https://doi.org/10.1016/j.tourman.2004.06.008

Evans, M. R., \& Chon, K. S. (1989). Formulating \& Evaluating Tou Rism Policy Using Importance-Performance Analysis. Hospitality Edu. \& Res. J., 13(3), 203-213. https://doi.org/10.1177/109634808901300320

Haber, S., \& Reichel, A. (2005). Identifying performance measures of small venture: The case of the tourism industry. J. of Small Bus. Management, 43(3), 257-286. https://doi.org/10.1111/j.1540-627x.2005.00137.x

Hall, C. M. (2001). Trends in ocean and coastal tourism: the end of the last frontier?. Ocean \& Coastal Management, 44(9), 601-618. https://doi.org/10.1016/s0964-5691(01)00071-0

Hosseini, S. Y., \& Bideh, A. Z. (2014). A data mining approach for segmentation-based importance-performance analysis: A new framework for developing customer retention strategies. Service Business, 8(2), 295-312. https://doi.org/10.1007/s11628-013-0197-7

Hudson, S., \& Shephard, G. W. (1998). Measuring service quality at tourist destinations: An application of importance-performance analysis to an alpine ski resort. Journal of Travel \& Tourism Marketing, 7(3), 61-77. https://doi.org/10.1300/j073v07n03_04

Hunter, C. (1997). Sustainable tourism as an adaptive paradigm. Annals of Tourism Research, 24(4), 850-867. https://doi.org/10.1016/s0160-7383(97)00036-4

Hunter, W. C. (2010). Groomed spaces on Jeju Island: A typology of photographic representations for tourism. International Journal of Tourism Research, 12(6), 680-695. https://doi.org/10.1002/jtr.783

Jeju Tourism Organization. (2016). Travel - Leisure Sports. Retrieved from http://www.ijto.or.kr/english/

Jennings, G. (2007). Water-based tourism, sport, leisure, and recreation experiences. London: Routledge. https://doi.org/10.1016/b978-0-7506-6181-2.50005-1

Kim, H. Y., \& Ryu, S. Y. (2009). The local residents' study for influence perceptions on marine attractions development. Korea Journal of Tourism and Hospitality Research, 23(2), 21-36. 
Kwon, I. K. (2016). The analysis of service quality attributes of water leisure tourism and potential customer satisfaction improvement (PCSI) index based on Kano model in Busan. Korean Society of Sport and Leisure Studies, 66(1), 39-54.

Kozak, M., \& Rimmington, M. (1998). Benchmarking: Destination attractiveness and small hospitality business performance. International Journal of Contemporary Hospitality Management, 10(5), 184-188. https://doi.org/10.1108/09596119810227767

Lee, S. H., \& Yeo, H. K. (2007). Analysis of structural relations of psychological decision making process on marine tourist. Korean Journal of Hospitality \& Tourism, 16(2), 203-216.

Leiper, N. (2004). Tourism management. Sydney, Australia: Pearson Education. https://doi.org/10.1016/j.tourman.2005.10.013

Leisen, B. (2001). Image segmentation: The case of a tourism destination. Journal of Services Marketing, 15(1), 49-66. https://doi.org/10.1108/08876040110381517

Litvin, S. W., \& Ling, S. N. S. (2001). The destination attribute management model: An empirical application to Bintan, Indonesia. Tourism Management, 22(5), 481-492. https://doi.org/10.1016/s0261-5177(01)00003-6

Matzler, K., Bailom, F., Hinterhuber, H. H., Renzl, B., \& Pichler, J. (2004). The asymmetric relationship between attribute level performance and overall customer satisfaction: A reconsideration of the importance-performance analysis. Industrial Marketing Management, 33(4), 271-277. https://doi.org/10.1016/s0019-8501(03)00055-5

Martilla, J. A., \& James, J. C. (1977). Importance-performance analysis. The Journal of Marketing, 77-79.

Oh, S. H., \& Ko, K. S. (2006). Attractive of island as tourist destination: A comparative study of Jeju in Korea and Okinawa in Japan. International Journal of Tourism Sciences, 30(2), 201-216.

Orams, M. B. (1988). Marine tourism: Development, impacts, and management. London: Routledge. https://doi.org/10.4324/9780203197110

Orams, M. B. (2002). Feeding wildlife as a tourism attraction: A review of issues and impacts. Tourism Management, 23(3), 281-293. https://doi.org/10.1016/s0261-5177(01)00080-2

Pike, S. (2002). The use of importance-performance analysis to identify determinant short-break destination attributes in New Zealand. Pacific Tourism Review, 6(1), 23-33. https://doi.org/10.1177/0047287502239054

Rial, A., Rial, J., Varela, J., \& Real, E. (2008). An application of importance-performance analysis (IPA) to the management of sport centres. Managing Leisure, 13(3-4), 179-188. https://doi.org/10.1080/13606710802200878

Richards, G. (2002). Tourism attraction systems: Exploring cultural behavior. Annals of Tourism Research, 29(4), 1048-1064. https://doi.org/10.1016/s0160-7383(02)00026-9

Ryan, C. (2003). Recreational tourism: Demand and impacts. Clevedon, UK: Channel View Press.

Seo, J. H., Park, S. Y., \& Yu, L. (2009). The analysis of the relationships of Korean outbound tourism demand: Jeju Island and three international destinations. Tourism Management, 30(4), 530-543. https://doi.org/10.1016/j.tourman.2008.10.013

Smith, A. C., \& Stewart, B. (2007). The travelling fan: Understanding the mechanisms of sport fan consumption in a sport tourism setting. $J$ of Sport \& Tourism,12(3),155-181. https://doi.org/10.1080/14775080701736924

Thornton, P. R., Shaw, G., \& Williams, A. M. (1997). Tourist group holiday decision-making and behavior: The influence of children. Tourism Management, 18(5), 287-297. https://doi.org/10.1080/09669580208667174

Twining-Ward, L., \& Butler, R. (2002). Implementing STD on a small island: Development and use of sustainable tourism development indicators in Samoa. Journal of Sustainable Tourism, 10(5), 363-387.

Wilson, C., \& Tisdell, C. (2003). Conservation and economic benefits of wildlife-based marine tourism: Sea turtles and whales as case studies. Human Dimensions of Wildlife, 8(1), 49-58. https://doi.org/10.1080/10871200390180145

\section{Copyrights}

Copyright for this article is retained by the author(s), with first publication rights granted to the journal.

This is an open-access article distributed under the terms and conditions of the Creative Commons Attribution license (http://creativecommons.org/licenses/by/4.0/). 